\title{
ERRATUM
}

Open Access

\section{Erratum to: 12th WINFOCUS world congress on ultrasound in emergency and critical care}

Edina Ćatić Ćuti ${ }^{*}$, Nadan Rustemović ${ }^{2}$ and Dražen Perkov²

\section{Erratum to: Crit Ultrasound J 2016, 8(Suppl 1):12 DOI 10.1186/s13089-016-0046-8}

Following publication of the original article [1], it was brought to our attention that the third author, Dražen Perkov, was missing from the author list of A15 (The challenge of AAA: unusual case of obstructive jaundice). We would like to apologise for any inconvenience caused.

\section{Author details}

${ }^{1}$ General Hospital Zabok and Hospital of Croatian Veterans, Zabok, Croatia.

${ }^{2}$ University Hospital Zagreb, Zagreb, Croatia.

The online version of the original article can be found under doi:10.1186/s13089-016-0046-8.

Received: 3 October 2016 Accepted: 3 October 2016

Published online: 24 October 2016

\section{Reference}

1. The Authors et al (2016) 12th WINFOCUS world congress on ultra-

sound in emergency and critical care. Crit Ultrasound J 8(Suppl 1):A15.

doi:10.1186/s13089-016-0046-8

\footnotetext{
*Correspondence: edina3110@gmail.com

${ }^{1}$ General Hospital Zabok and Hospital of Croatian Veterans, Zabok,

Croatia

Full list of author information is available at the end of the article
} provided you give appropriate credit to the original author(s) and the source, provide a link to the Creative Commons license, and indicate if changes were made. 